\title{
Teknologi Informasi dalam Integrasi Supply Chain dan Pertukaran Informasi Terhadap Performa Supply Chain
}

\author{
Wiji Safitri' ${ }^{1}$, Miftakul Huda ${ }^{2}$ \\ ${ }^{1,2}$ Universitas Pelita Bangsa \\ Cikarang, Indonesia
}

e-mail: ${ }^{1}$ wijisafitri@ pelitabangsa.ac.id, ${ }^{2}$ miftakulhuda@pelitabangsa.ac.id

\begin{abstract}
Informasi Artikel
Diterima: 01-10-2021

Direvisi: 11-11-2021

Disetujui: 30-01-2022

Abstrak

UMKM sebagai sektor penggerak ekonomi mengalami penurunan performa di masa pandemi. Khusunya performa supply chain, teknologi dinilai sebagai hal yang dapat meningkatkan performa supply chain. Selain teknologi diduga ada hal lain yaitu Integrasi Supply Chain dan Pertukaran Informasi. Penelitian ini bertujuan untuk mengetahui hubungan antara Teknologi Informasi, Integrasi Supply Chain, dan Pertukaran Informasi dengan Performa Supply Chain. Penelitian ini merupakan penelitian explanatory. Data diperoleh dengan menyebarkan kuesioner kepada 200 UMKM. Metode yang digunakan dalam penelitian ini menggunakan Structural Equation Model yang menggunakan softwareIBM Amos 26 untuk olah data. Hasil penelitian menyebutkan Peran Teknologi Informasi terhadap Integrasi Supply Chain dan Pertukaran Informasi adalah positif signifikan, selain itu peran Integrasi Supply Chain terhadap Performa Supply Chain juga positif signifikan. Teknologi Informasi tidak signifikan secara langsung berpengaruh terhadap Performa Supply Chain begitu juga Pertukaran Informasi tidak signifikan pengaruhnya terhadap Performa Supply Chain. Dengan ini, UMKM perlu meningkatkan kesadarannya dalam pemanfaatan teknologi informasi karena dalam peningkatan integrasi supply chain akan mempengaruhi terhadap performa supply chain yang akan bersama - sama dengan mitra untuk berkordinasi dalam penyampaian barang yang lebih cepat kepada konsumen akhir dengan biaya lebih rendah. Selain itu, perlu dilakukan pengkajian mengenai peran teknologi secara tidak langsung terhadap performa supply chain.
\end{abstract}

Kata Kunci: TeknologiInformasi ; Performa Supply Chain ; IntegrasiSupply Chain.

\begin{abstract}
MSMEs as the economic driving sector experienced a decline in performance during the pandemic. Especially supply chain performance, information technology is seen that can improve supply chain performance. Besides that Supply Chain Integration and Information Exchange. This study aims to determine the relationship between Information Technology, Supply Chain Integration, and Information Exchange with Supply Chain Performance. This research is explanatory. Data were obtained by distributing questionnaires to 200 MSMEs. The method used Structural Equation Model using IBM Amos 26. The results state that the role of Information Technology on Supply Chain Integration and Information Exchange is significantly positive, besides that the role of Supply Chain Integration on Supply Chain Performance is also significantly positive. Information Technology does not have a significant direct effect on Supply Chain Performance as well as Information Exchange does't significantly affect Supply Chain Performance. With this, MSMEs need to increase their awareness of the use of information technology because increasing supply chain integration will affect supply chain performance, which will work together with partners to coordinate faster delivery of goods to end consumers at lower costs. In addition, it is necessary to conduct an assessment of the indirect role of technology on supply chain performance.
\end{abstract}

Keywords: Information Technology, Supply Chain Performance, Supply Chain Integration.

\section{Pendahuluan}

Pandemi Covid berimbas pada kondisi ekonomi Negara. Khususnya Indonesia, dampak besar tersebut mempengaruhi keberlangsungan UMKM. Dari hasil survei Asian Development Bank (ADB) sejumlah 48,6\% UMKM Indonesia gulung tikar (Media Indonesia, 2021).Berdasarkan data LIPI mengenai survei kinerja UMKM Indonesia, sejumlah 94,69\% mengalami penurunan penjualan (LIPI, 2020). Dari penurunan tersebut akan berdampak pada profit sementara biaya produksi tetap dan akan meningkat (Junida, 2020). 
Sisi lain UMKM di masa pandemi adalah sebagai pemulihan terhadap ekonomi. UMKM dituntut mampu beradaptasi dengan pemanfaatan teknologi informasi (kompas, 2021). Namun kenyataannya masih 13\% UMKM yang sudah memanfaatkan teknologi (Purnamasari, 2020).Menurut Menteri Koordinator Bidang Kemaritiman dan Investasi, UMKM Indonesia belum melek teknologi yang merupakan solusi bagi UMKM di masa pandemi (Hikam, 2020).

Teknologi Informasi berperan besar dalam supply chain terutama dalam kolaborasi dan koordinasi (Binus, 2019). Penggunaan teknologi informasi mempunyai keuntungan dalam meningkatkan kinerja supply chain (Asmuni, 2014). Berdasarkan (Munizu, 2017) teknologi informasi mempunyai hubungan yang positif signifikan terhadap kinerja supply chain, mekanisme koordinasi yang baik antar pelaku rantai pasok dapat efektivitas aliran material, informasi, dan uang.

Teknologi Informasi (TI) adalah penggunaan sistem antar organisasi untuk berbagi informasi dan atau pemrosesan melintasi batas-batas organisasi(Jadhav, 2015).TI dianggap mampu memberikan nilai strategis dan operasional yang besar bagi organisasi(Afolayan et al., 2015). Dari sisi Supply Chain, teknologi memainkan peran penting dalam peningkatan performa Supply Chain(Jadhav, 2015).Selain itu, TI dianggap sebagai prasyarat kritis dalam Supply Chain(Varma \& Khan, 2014).

Teknologi mempunyai hubungan positif signifikan dengan Performa Supply Chain khususnya untuk efektivitas(Hendayani \& Febrianta, 2020). TI secara langsung mempunyai hubungan positif dengan Performa Supply Chain, kemudian TI mempunyai hubungan yang positif dengan Integrasi Supply Chain, serta TI mempunyai hubungan positif dengan Pertukaran Informasi(Sundram et al., 2020).

Secara praktikal supply chain adalah mengintegrasikan produk sampai kepada end user, diperlukan pemetaan strategi supply chain dengan meminimalkan pembelian dan meningkatkan kuantitas pemesanan suatu barang(Alfatiyah, 2020).

Fokus dari Kementerian Koperasi dan UKM adalah mendorong UMKM untuk memasuki rantai pasok global (Herman, 2019). Rasio keterlibatan UMKM di dalam rantai pasok global masih rendah $6,3 \%$ (Situmorang, 2021). Untuk mendorong UMKM dalam keterlibatan rantai pasok global, Kementerian Koperasi dan UKM mengintegrasikan rantai pasok UMKM yaitu pelaku koperasi, UMKM, dan IKM (Oktari, 2021).

Integrasi Rantai Pasok adalah dimana perusahaan dapat bekerjasama strategis dengan mitra rantai pasok dan mengelola proses intra dan antar organisasi secara kooperatif yang akan diberikan kepada pelanggan akhir dengan biaya rendah dan kecepatan maksimum(Dametew et al., 2016). Integrasi Rantai Pasok adalah koordinasi strategis dan kolaborasi sumber daya perusahaan strategis dengan mitra lain dalam arsitektur bersama untuk peran mission-critical untuk memenuhi kebutuhan pemangku kepentingan (Som et al., 2019). Pertukaran informasi tidak bisa berjalan dengan lancar hanya mengandalkan TI dibutuhkan koordinasi dan kontribusi yang baik antar rantai pasok atau Integrasi Supply Chain(Nabila \& Er, 2019).

Integrasi Supply Chain mempunyai hubungan positif terhadap Performa Supply Chain(Sundram et al., 2020). Hal yang sama disebutkan bahwa Integrasi Supply Chain berpengaruh signifikan terhadap Performa Supply Chain(Mofokeng \& Chinomona, 2019).

Dalam pertukaran informasi akan memunculkan informasi dan gagasan baru yang sebelumnya belum pernah ada (Binus.ac.id, 2017). Salah satu cara UMKM agar dapat bertahan di masa pandemi adalah dengan melakukan pertukaran informasi yang dapat dilakukan dengan masuk ke dalam suatu wadah/komunitas (liputan6.com, 2021).

Pertukaran informasi adalah mendistribusikan informasi, yang berguna untuk system, orang, atau unit organisasi(Lotfi et al., 2013). Tanpa pertukaran informasi yang tepat dengan konsumen dan supplier organisasi kehilangan kesempatan membagikan rencana produk(Subburaj et al., 2020).

Pertukaran informasi memberikan hubungan positif signifikan dengan Performa Supply Chain, Ketika aliran informasi yang efisien dalam rantai pasokan ditekankan pada transfer produk dan bahan, pengurangan inventaris dan pemanfaatan sumber daya yang efektif menjadi tercapai(Sundram et al., 2020). Pertukaran informasi meningkatkan Performa Supply Chain dari keseluruhan biaya inventori dan laju pemenuhan ketika variasi permintaan kecil(Nabila \& Er, 2019).

Kapasitas rantai pasokan untuk mengirimkan dengan biaya logistik minimum produk pada waktu yang tepat dan di lokasi yang benar disebut sebagai Performa Supply Chain(Ucenic \& Ratiu, 2017). Pencapaian Performa Supply Chain terdapat tiga tingkatan pada Integrasi Supply Chain yaitu integrasi dengan pemasok, integrasi dengan pelanggan, dan integrasi intra-organisasi(Kocoglu et al., 2011).

Teknologi Informasi, Integrasi Supply Chain, dan Pertukaran Informasi mempunyai hubungan signifikan terhadap Peningkatan Performa Supply Chain (Sundram et al., 2020). (Nabila \& Er, 2019) menyebutkan hal yang sama selain itu menemukan model konseptual untuk peningkatan Performa Supply Chain.

Timbulnya permasalahan di atas, perlu dikaji lebih lanjut mengenai performa Supply Chain UMKM, bagaimana UMKM membuat suatu jaringan yang bekerja secara bersama - sama untuk menciptakan dan mengantarkan produk sampai ke tangan pemakai akhir. Sehingga perlu dilakukan identifikasi terhadap faktor yang mempunyai 
hubungan signifikan terhadap Performa Supply Chain UMKM Bekasi di masa pandemi COVID-19, diantaranya adalah Teknologi Informasi, Integrasi Supply Chain dan Pertukaran Informasi

Hubungan Teknologi Informasi (TI), Integrasi Supply Chain (ISC), Pertukaran Informasi (PI), dengan Performa Supply Chain (PSC).

Berikut adalah gambar model penelitian ini:

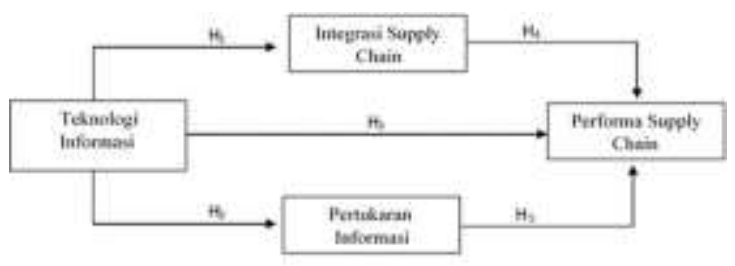

Sumber: Penulis, 2021

Gambar 1. Model Penelitian

Hipotesis dalam penelitian ini adalah :

1. Adanya hubungan positif signifikan antara TI dengan Integrasi Supply Chain.

2. Adanya hubungan positif signifikan antara TI dengan Pertukaran Informasi.

3. Adanya hubungan positif signifikan antara TI dengan Performa Supply Chain.

4. Adanya hubungan positif signifikan antara Integrasi Supply Chain dengan Performa Supply Chain.

5. Adanya hubungan positif signifikan antara Pertukaran Informasi dengan Performa Supply Chain.

Penelitian(Nabila \& Er, 2019)adalah Systematic Literature Review (SLR) yang membuat model konseptual dan mencari indikator variable TI, Integrasi Supply Chain, Pertukaran Informasi, serta Performa Supply Chain. Perbedaan dengan penelitian tersebut adalah penelitian ini langsung menguji objek penelitian yaitu UMKM Bekasi pada masa Pandemi COVID-19.

Perbedaan penelitian ini dengan penelitian (Hendayani \& Febrianta, 2020)adalah penelitian ini menggunakan variable Integrasi Supply Chain dan Pertukaran Informasi untuk mencari hubungan dengan Performa Supply Chain, kemudian penelitian ini dilakukan kepada UMKM Bekasi pada masa Pandemi COVID-19. Selain itu, penelitian(Hendayani \& Febrianta, 2020)menggunakan efektivitas dan efisien untuk mendeteksi Performa Supply Chain, sementara penelitian ini menggunakan indikator dari penelitian(Nabila \& Er, 2019) dan (Sundram et al., 2020).

Perbedaan penelitian ini dengan(Sundram et al., 2020)penelitian ini dilakukan pada UMKM di Indonesia, sementara penelitian(Sundram et al., 2020)dilakukan perusahaan manufaktur di Malaysia dan menggunakan variable Performa Perusahaan sebagai efek dari Performa Supply Chain.

\section{MetodePenelitian}

Jenis penelitian ini adalah penelitian causal dengan tujuan mengetahui hubungan antara: Teknologi Informasi terhadap Integrasi Supply Chain, Teknologi Informasi terhadap Pertukaran Informasi, Teknologi Informasi terhadap Performa Supply Chain, Integrasi Supply Chain terhadap Performa Supply Chain, dan Pertukaran Informasi terhadap Performa Supply Chain. Penelitian ini termasuk jenis penelitian penjelasan (explanatoryresearch), yaitu penelitian yang bertujuan untuk menjelaskan dan menejelaskan informasi deksriptif. Di dalam Eksplanatory pertanyaan yang diajukan adalah "mengapa" dan "bagaimana", berbeda dengan penelitian deskriptif yang menanyakan jenis pertanyaan "apa"(Gray, 2014).

Pengambilan subjek dalam penelitian mengikuti pedomandari (Santosa, 2018) yaitu secara umum, sampel yang digunakanuntuk SEM adalah:

1. Untuk model SEM dengan jumlah variable laten (konstruk) sampai dengan lima buah, dan setiap konstruk dijelaskan oleh tiga atau lebih indikator, jumlah sampel 100-150 data sudah dianggap memadai.

2. Namun, jika pada kondisi di atas korelasi antara indikator dengan konstruk tidak kuat (di bawah 0,6), jumlah sampel sebaiknya perlu ditingkatkan sampai 300 data.

3. Pada model yang sangat kompleks, seperti terdapat lebih dari enam konstruk, atau ada konstruk dengan jumlah indikator kurang dari tiga per konstruk, jumlah sampel sebaiknya mencapai 500 data.

Namun, pedoman tersebut tidak mengikat, karena dalam praktik pengumpulan sampel terkendala tenaga, dana, waktu, dan ciri - ciri populasi tidak memungkinkan tersedianya sampel dalam jumlah memadai. Sehingga jumlah sampel sebanyak 200 pada umumnya dapat diterima sebagai sampel yang representative dalam analisis SEM (Santosa, 2018). Berdasarkan pada ketentuan di atas subjek yang diambil dalam penelitian ini adalah 200 UMKM yang berada di Bekasi pada masa Pandemi COVID-19.

Teknik analisis menggunakan Structural Equation Modeling (SEM). SEM adalah pemodelan statistika yang melibatkan hubungan antar variable dan juga model indikator secara simultan (Solimun \& Nurjannah, 2017). Pendekatan SEM umum digunakan pada berbagai disiplin ilmu, uji model prediksi ditujukan untuk menguji hubungan sebabakibat (kausalitas) diantara variable ataukonstruk model yang diajukan (Rachbini \& Rachbini, n.d.). SEM adalah metode penelitian hubungan, yaitu mengukur skala, Batasan rentang nilai data, data 
hilang, outliers, non-linearity, dan non-normality data yang mempengaruhi variance-covariance diantara variable (Schumacker \& Lomax, 2016). Olah data dalam penelitian ini menggunakan IBM SPSS Amos versi 26. Untuk variable agar memudahkan dalam pengolahan data disingkat sebagai berikut: TI (TeknologiInformasi), ISC (Integrasi Supply Chain), PI (Pertukaran Informasi), dan PSC (Performa Supply Chain).

\section{Hasil danPembahasan}

\subsection{Karakteristik Responden}

Penyebaran kuesioner dilakukan kepada kurang lebih 300 responden, sebanyak 202 kuesioner kembali dan sejumlah 200 kuesioner yang telah diisi dengan lengkap. Berikut adalah beberapa data karakteristik responden dari UMKM Bekasi:

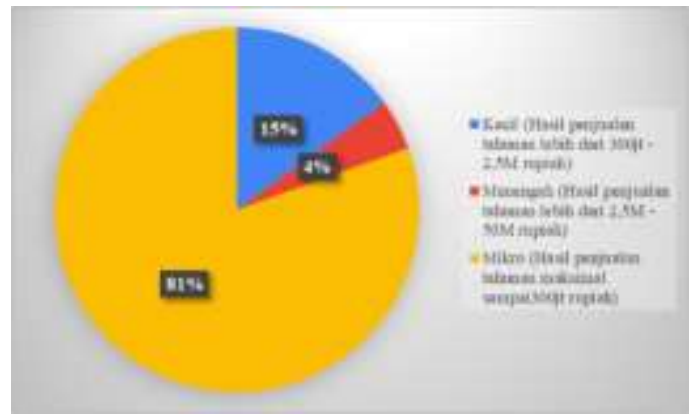

Sumber: Olah Data Peneliti

\section{Gambar 2. UMKM Bekasi Berdasarkan Skala Usaha}

Pada Gambar 2. diketahui bahwa responden didominasi oleh usaha dengan skala Mikro dengan hasil penjualan tahunan maksimal sampai 300 juta rupiah sejumlah $81 \%$. Untuk UMKM yang berskala menengah paling kecil yaitu 4\%. Hal ini mengindikasikan bahwa UMKM Bekasi masih didominasi oleh usaha dengan skala Mikro. Usaha skala mikro diindikasikan dengan modal kecil dari pada jenis skala usaha yang lain.

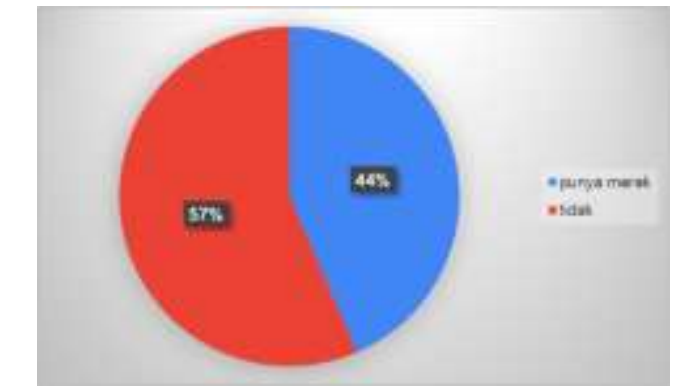

Sumber: Olah Data Peneliti Gambar 3. Karakteristik Responden Berdasarkan
ada/tidaknya Merek

Berdasarkan Gambar 3. UMKM Bekasi masih didominasi oleh UMKM yang belum mempunyai merek sejumlah 57\%. Tidak terpaut jauh dengan UMKM yang sudah mempunyai merek yaitu
$44 \%$.

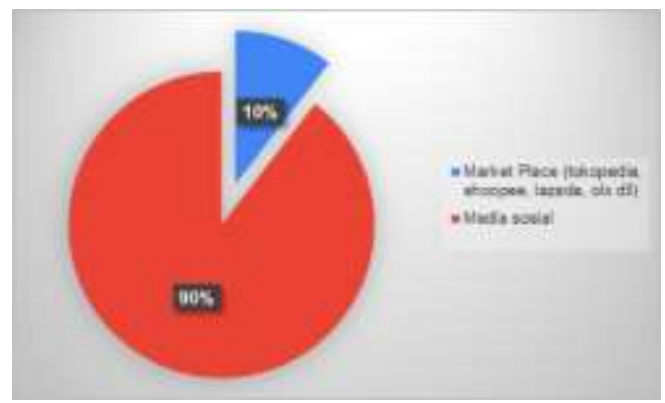

Sumber: Data yang diolah Peneliti

Gambar 4. Karakteristik Responden Berdasarkan Media yang Digunakan

Berdasarkan Media yang dipergunakan dalam melakukan aktivitas bisnisnya, UMKM Bekasi didominasi oleh Media Sosial sejumlah $90 \%$. Dibandingkan media sosial, masih sedikit yang mempergunakan market placeseperti tokokedia, shopee, lazada, dll dalam proses bisnisnya.

\subsection{Confirmatory Factor Analysis (CFA)}

Confirmatory Factor Analysis dipergunakan untuk menguji pola hubungan antar konstruk laten termasuk juga untuk mengetahui apakah indikator menggambarkan sebuah konstruk (Wijaya \& Spss, 2011). Jika ada yang tidak sesuai maka indikator tersebut dihapus dan diuji kembali sehingga mendapatkan indikator - indikator yang menggambarkan konstruk tersebut. Uji validitas diukur dengan cara melihat nilai factor loading standar, jika >0,5 maka dinyatakan valid. Kemudian untuk nilai $\mathrm{p}$ value $<0,05$ maka indikator dinyatakan signifikan (Haryono \& Wardoyo, 2015). Hasil dari uji tersebut adalah sebagai berikut:

Tabel 1.Regression Weight

\begin{tabular}{|c|c|c|c|}
\hline & Estimated & C.R. & $\mathrm{P}$ \\
\hline $\mathrm{TI} .1 \leftarrow \mathrm{TI}$ & 1 & & $* * *$ \\
\hline $\mathrm{TI} .2 \leftarrow \mathrm{TI}$ & 1,056 & 5,124 & $* * *$ \\
\hline $\mathrm{TI} .3 \leftarrow \mathrm{TI}$ & 1,212 & 5,73 & $* * *$ \\
\hline $\mathrm{TI} .4 \leftarrow \mathrm{TI}$ & 1,03 & 5,062 & $* * *$ \\
\hline TI. $5 \leftarrow$ TI & 0,947 & 4,601 & \\
\hline ISC. $1 \leftarrow$ ISC & 1 & & $* * *$ \\
\hline ISC. $2 \leftarrow$ ISC & 0,911 & 10,686 & $* * *$ \\
\hline ISC. $3 \leftarrow$ ISC & 0,937 & 8,379 & $* * *$ \\
\hline ISC. $4 \leftarrow$ ISC & 0,742 & 8,613 & \\
\hline $\mathrm{PI} .1 \leftarrow \mathrm{PI}$ & 1 & & $* * *$ \\
\hline $\mathrm{PI} .2 \leftarrow \mathrm{PI}$ & 1,098 & 8,402 & $* * *$ \\
\hline $\mathrm{PI} .3 \leftarrow \mathrm{PI}$ & 0,943 & 7,616 & $* * *$ \\
\hline $\mathrm{PI} .4 \leftarrow \mathrm{PI}$ & 1,037 & 7,843 & $* * *$ \\
\hline $\mathrm{PI} .5 \leftarrow \mathrm{PI}$ & 1,166 & 8,617 & $* * *$ \\
\hline PI.6ட PI & 0,999 & 8,384 & \\
\hline $\begin{array}{l}\text { PSC. } 1 \leftarrow \\
\text { PSC }\end{array}$ & 1 & & $* * *$ \\
\hline $\begin{array}{l}\text { PSC. } 2 \leftarrow \\
\text { PSC }\end{array}$ & 0,983 & 10,767 & $* * *$ \\
\hline $\begin{array}{l}\text { PSC. } 3 \leftarrow \\
\text { PSC }\end{array}$ & 1,165 & 13,785 & $* * *$ \\
\hline $\begin{array}{l}\text { PSC. } 4 \leftarrow \\
\text { PSC }\end{array}$ & 0,9 & 10,213 & $* * *$ \\
\hline
\end{tabular}


PSC.5 $\quad 1,057 \quad 12,01 \quad * * *$ PSC

Dari Tabel 1 dapat diketahui bahwa nilai factor loading pada kolom estimates $>0,5$ dan nilai probabilitas $<0,05$ (nilai signifikansi $* * *$ berarti $<0,001$ ) sehingga seluruh item indikator pada tabel tersebut dinyatakan valid dan signifikan.

\subsection{Reliabilitydan Normalitas}

Reliability adalah derajat ketepatan suatu skor dalam sampel yang diukur dengan nilai Cronbach's alpha dengan nilai 0,9 mengindikasikan sangat baik, 0,8 baik, dan 0,7 mengindikasikan cukup (Uyun et al., 2021). Ukuran reliabilitas yang lain adalah variance extracted sebagai pelengkap construct reliability dengan nilai $>0,5$ yang dihitung dengan rumus berikut (Haryono \& Wardoyo, 2015):

$$
\begin{aligned}
& \text { Construct } \quad=\frac{(\Sigma s t \text { loading })^{2}}{(\Sigma s t \text { loading })^{2}+\Sigma} \ldots \ldots \ldots . . .(1) \\
& \text { Variance Extracted }=\frac{\Sigma \text { std loading }{ }^{2}}{\Sigma s t \text { loading }{ }^{2}+\Sigma \text { gj }} \ldots \ldots \ldots \ldots . .(2)
\end{aligned}
$$

Tabel 2.Nilai Reliabilitas

\begin{tabular}{lcc}
\hline & Nilai \\
\hline TI & 0,68 \\
ISC & 0,88 \\
PI & 0,89 \\
PSC & 0,94 \\
\hline Sumber : Olah data Peneliti &
\end{tabular}

Berdasarkan pada Tabel 2 dapat dilihat bahwa semua nilai $>0,5$ yang menyatakan bahwa variabel reliabel.

Berdasarkan pengalaman empiris para pakar statistik untuk data yang banyaknya $n>30$ maka sudah dapat diasumsikan berdistribusi normal karena bisa dikatakan sebagai sampel besar (Cahyono, 2018). Sehingga karena sampel dalam penelitian ini sejumlah 200 responden maka tidak dilakukan uji normalitas.

\subsection{Goodness of Fit (GOF) Test}

Goodness of Fit mengukur kesesuaian input observasi atau matriks kovarians / korelasi dengan prediksi dari model yang diajukan (Haryono \& Wardoyo, 2015). Kriteria FIT dari suatu model mengikuti indikator sebagai berikut:

Tabel 3. Standar Goodness of Fit (GOF) Test

\begin{tabular}{ll}
\hline $\begin{array}{l}\text { Goodness of Fit } \\
\text { Index }\end{array}$ & $\begin{array}{l}\text { Cut }- \text { off } \\
\text { Value }\end{array}$ \\
\hline $\mathrm{X}^{2}=$ Chi -square & $<200$ \\
(df $=152$ & \\
Sign.Probability & $\geq 0.05$ \\
Df & $\geq 0$ \\
CMIN/DF & $\leq 2.00$ \\
GFI & $\geq 0.90$ \\
AGFI & $\geq 0.90$ \\
CFI & $\geq 0.90$
\end{tabular}

\section{RMSEA $\leq 0.08$ \\ Sumber: (Bahri \& Zamzam, 2021).}

Dari hasil olah data AMOS 26 dan setelah dilakukan uji bertahap sehingga diperoleh model yang fit/tepat.Berikut gambar model struktural yang menggambarkan hubungan antar variabel laten atau antar variabel eksogen dan endogen:

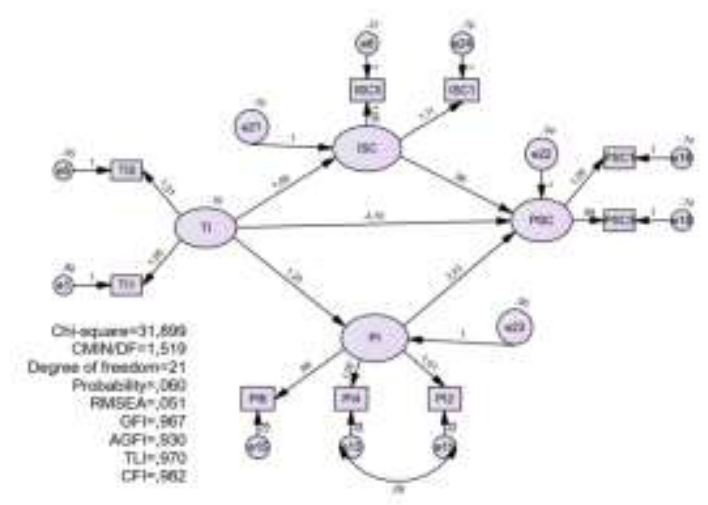

Sumber: Olah Data Peneliti

\section{Gambar 5. Model Struktural}

Dari Gambar 5 terlihat bahwa nilai Chisquare $<200$ dan nilai probability $>0,05$ lebih lengkap pada Tabel 4. Pada bagian Teknologi Informasi terdiri dari TI1 yaitu UMKM secara aktif dalam menginstruksikan kepada konsumen mengenai situs web/media sosial yang digunakan dan TI5 yaitu UMKM Mengadopsi transaksi online untuk mengurangi operasional biaya. Untuk pertukaran informasi terdiri dari PI2 yaitu mitra UMKM berbagi informasi dengan Pelaku UMKM, PI4 yaitu mitra UMKM berbagi proses bisnis inti dengan Pelaku UMKM, dan PI6 yaitu UMKM dan mitra saling menjaga informasi yang dapat mempengaruhi mitra lainnya.

Integrasi supply chain terdiri dari ISC1 dan ISC3 yaitu UMKM menjalin kontak yang sering dalam rantai pasokan dan UMKM memperluas rantai pasokannya melampaui pelanggan/pemasok. Sementara untuk Performa Supply Chain terdiri dari PSC 1 dan PSC3 yaitu UMKM mendapat biaya yang akurat dalam pasokan barang dan UMKM telah meningkatkan koordinasi dengan pemasok.

Tabel 4. Hasil Pengujian Goodnees of Fit Test

\begin{tabular}{lll}
\hline $\begin{array}{l}\text { Goodness of Fit } \\
\text { Index }\end{array}$ & Nilai & Keterangan \\
\hline $\begin{array}{l}\mathrm{X}^{2}=\text { Chi }- \\
\text { square }(\mathrm{df}=152\end{array}$ & 31,899 & Baik \\
Sign.Probability & 0,060 & Baik \\
Df & 21 & Baik \\
CMIN/DF & 1,519 & Baik \\
GFI & 0,967 & Baik \\
AGFI & 0,930 & Baik \\
CFI & 0,982 & Baik \\
RMSEA & 0,051 & Baik \\
\hline \multicolumn{2}{l}{ Sumber: Olah Data Peneliti } &
\end{tabular}


Pada Tabel 4 terlihat bahwa semua kriteria untuk Goodness of Fit test telah memenuhi sehingga model telah FIT/sesuai. Teknologi Informasi yang terdiri dari TI1, TI2, TI3, TI4, dan TI5 setelah dilakukan uji FIT terhadap model, terdapat dua yang memenuhi syarat FIT yaitu TI1 dan TI5. Pertukaran Informasi yang terdiri dari PI1, PI2, PI3, PI4, PI5, dan PI6 setelah dilakukan uji FIT Terdapat tiga yang memenuhi syarat FIT yaitu PI2, PI4, dan PI6. Integrasi Supply Chain yang diwakili ISC1, ISC2, ISC3, dan ISC4 terdapat dua yang memenuhi syarat FIT yaitu ISC1 dan ISC3. Performa Supply Chain yang terdiri dari PSC1, PSC2, PSC3, PSC4, dan PSC5 setelah dilakukan uji FIT terdapat dua yang memenuhi syarat FIT yaitu PSC1 dan PSC3.

\subsection{Uji Hipotesis dan Pembahasan}

Setelah kriteria untuk Goodness of Fit terpenuhi/baik, selanjutnya adalah melakukan uji hipotesis pada model struktural. Hubungan antar konstruk ditujukan dengan hasil regression weight.

Tabel 5. Regression Weight

\begin{tabular}{|c|c|c|c|c|}
\hline & Estimate & S.E. & C.R. & $\mathbf{P}$ \\
\hline $\mathrm{ISC} \leftarrow \mathrm{TI}$ & 1,087 & ,221 & 4,922 & $* * *$ \\
\hline $\mathrm{PI} \leftarrow \mathrm{TI}$ & 1,245 & 258 & 4,833 & $* * *$ \\
\hline $\mathrm{PSC} \leftarrow$ ISC & ,976 & 324 & 3,011 & ,003 \\
\hline $\mathrm{PSC} \leftarrow \mathrm{PI}$ & 3,234 & 21,925 &, 148 & ,883 \\
\hline $\mathrm{PSC} \leftarrow \mathrm{TI}$ & $-4,105$ & 27,569 &,- 149 &, 882 \\
\hline
\end{tabular}

Sumber: Olah Data Peneliti

Pengaruh TI (Teknologi Informasi) terhadap ISC (Integrasi Supply Chain) diperoleh nilai $\mathrm{p}=* * *<0,05$ sehingga hipotesis diterima yaitu Teknologi Informasi berpengaruh positif signifikan terhadap Integrasi Supply Chain pada UMKM Bekasi di masa pandemi Covid-19. Semakin UMKM Bekasi memanfaatkan teknologi Informasi maka semakin baik integrasi supply chain. Bagaimana UMKM tersebut berhubungan dengan mitra untuk mengantarkan barang sampai ke tangan konsumen akhir sehingga biaya yang dikeluarkan akan semakin kecil. Hal ini diharapkan dapat mengurangi biaya dan meningkatkan kecepatan barang untuk konsumen akhir (Dametew et al., 2016).

TI (Teknologi Informasi) berpengaruh positif signifikan terhadap PI (Pertukaran Informasi) sehingga hipotesis penelitian diterima. Hal inidiindikasikan dengan nilai $\mathrm{p}=* * *<0,05$. Semakin baik UMKM menggunakan Teknologi Informasi dalam proses bisnis maka akan meningkatkan Pertukaran Informasi. Tanpa pertukaran informasi yang tepat dengan konsumen dan supplierUMKM kehilangan untuk membagikan rencana produk (Subburaj et al., 2020). Dengan teknologi informasi pertukaran informasi ini akan semakin lebih cepat. Hal yang sama dikemukakan oleh (Sundram et al., 2020) pada organisasi di Malaysia Teknologi informasi mempunyai pengaruh yang positif signifikan terhadap Pertukaran informasi. Media yang dominan digunakan oleh pelaku UMKM Bekasi adalah media sosial yaitu 90\%. Dengan media sosial ini UMKM dapat melakukan pertukaran informasi dengan cepat sehingga akan sampai dengan cepat juga barang kepada konsumen akhir.

ISC (Integrasi Supply Chain) mempunyai pengaruh positif signifikan terhadap PSC (Performa Supply Chain), dengan ini hipotesis dalam penelitian ini diterima. Hal ini diindikasikan dengan nilai $\mathrm{p}=$ $0,03<0,05$. Semakin baik integrasi supply chain yang dilakukan oleh UMKM Bekasi maka akan semakin baik performa supply chain.Pertukaran informasi tidak bisa berjalan dengan lancar hanya mengandalkan TI dibutuhkan koordinasi dan kontribusi yang baik antar rantai pasok atau Integrasi Supply Chain (Nabila \& Er, 2019). Hal yang sama dikemukakan oleh (Mofokeng \& Chinomona, 2019)bahwa integrasi supply chain berperan positif signifikan terhadap performa suppy chain.

PI (Pertukaran Informasi) tidak berpengaruh signifikan terhadap terhadap PSC (PerformaSupply Chain) diindikasikan dengan nilai $\mathrm{p}=0,883>0,05$ dengan ini hipotesis dalam penelitian ditolak. Penelitian sebelumnya (Nabila \& Er, 2019) menyebutkan diduga adanya hubungan yang signifikan diantara pertukaran informasi terhadap performa supply chain. Dalam Pertukaran informasi dari hasil penelitian setelah dilakukan uji FIT Model, PI2 dan PI4 terdapat korelasi sehingga hasil yang diperoleh dari model adalah FIT. PI2 yaitu mitra UMKM berbagi informasi dengan Pelaku UMKM, PI4 yaitu mitra UMKM berbagi proses bisnis inti dengan Pelaku UMKM. Dalam penelitian sebelumnya tidak dijelaskan bahwa perlunya hubungan yang saling berkaitan untuk berbagi informasi dan berbagi proses bisnis inti diantara pemasok bagi UMKM. Ketika hal ini dihubungkan, model yang diperoleh adalah FIT, namun tidak berpengaruh signifikan terhadap Performa Supply Chain.

TI (Teknologi Informasi) tidak berpengaruh signifikan terhadap PSC (Performa Supply Chain) diindikasikan dengan nilai $\mathrm{p}=0,882>0,05$ sehingga hipotesis dalam penelitian ini ditolak. Dalam (Nabila \& Er, 2019) diduga adanya hubungan yang positif sifnifikan antara Teknologi Informasi dengan Performa Supply Chain, namun setelah diujikan kepada UMKM Bekasi, TI tidak berpengaruh signifikan terhadap PSC. Setelah dilakukan uji model FIT, Teknologi Informasi terdiri dari TI1 dan TI5 yaitu UMKM secara aktif dalam menginstruksikan kepada konsumen mengenai situs web/media sosial yang digunakan dan UMKM Mengadopsi transaksi online untuk mengurangi operasional biaya. Dalam pengadopsan terhadap teknologi mayoritas UMKM menggunakan media sosial sebagai sarana bisnis. Sementara masih rendahnya UMKM yang memanfaatkan teknologi yaitu $13 \%$. Dari hasil sebelumnya bahwa mayoritas 
UMKM Bekasi didominasi oleh usaha dengan skala mikro dengan maksimal hasil penjualan per tahun 300 juta rupiah, perlu adanya kesadaran pada tingkat usaha tersebut dalam pemanfaatan teknologi informasi sehingga dapat meningkatkan performa supply chain.

\section{Kesimpulan}

UMKM sebagai sektor penggerak ekonomi dan pada saat kondisi pandemi mengalami penurunan kinerjanya perlu diidentifikasi apa yang dapat meningkatkan performa UMKM. Khususnya untuk performa supply chain pada UMKM sangat penting karena berkontribusi dari hulu sampai hilir dimana barang sampai kepada konsumen akhir. Setelah dilakukan kajian lebih lanjut mengenai hal apa yang dapat meningkatkan performa supply chain UMKM Bekasi terutama pada saat pandemi ada beberapa hal yaitu Integrasi Supply Chain. Hal ini senada dengan hasil penelitian yaitu integrasi supply chain berpengaruh positif signfikan terhadap performa supply chain. Dalam melakukan proses bisnisnya UMKM perlu untuk menjalin kontak yang sering dalam rantai pasokan dan UMKM perlu memperluas rantai pasokannya melampaui pelanggan/pemasok. Hal ini telah dikonfirmasi dapat meningkatkan performa supply chain secara signifikan.

Integrasi supply chain berperan bagaimana UMKM berkoordinasi dengan mitra sehingga barang dapat sampai kepada konsumen akhir dengan cepat dan biaya yang lebih rendah. Hal ini tentunya tidak serta merta Integrasi supply chain dapat naik, peningkatan terhadap integrasi supply chain dapat dilakukan dengan cara peningkatan terhadap teknologi informasi dalam proses bisnis UMKM. Hal ini senada dengan hasil penelitian bahwa Teknologi informasi mempunyai pengaruh positif signifikan terhadap interasi supply chain. Peningkatan Integrasi melalui teknologi informasi dapat dilakukan dengan cara menginstruksikan kepada konsumen mengenai situs web/media sosial yang digunakan dan Mengadopsi transaksi online untuk mengurangi operasional biaya, hal ini telah dikonfirmasi bahwa teknologi informasi dapat meningkatkan integrasi supply chain.

Di sisi lain, Teknologi Informasi mempunyai peran yang penting juga pada UMKM untuk peningkatan pertukaran informasi. Pertukaran informasi dilakukan dari mulai proses mengadaan barang sebelum diproduksi sampai barang tersebut sampai kepada konsumen akhir. Hal ini senada dengan hasil penelitian bahwa Teknologi informasi berpengaruh positif signifikan terhadap pertukaran informasi. Pertukaran melalui teknologi informasi itu sendiri mengenai hal yang berkaitan dengan berbagi informasi dengan Pelaku UMKM, berbagi proses bisnis inti dengan Pelaku UMKM, dan saling menjaga informasi yang dapat mempengaruhi mitra lainnya. Dari sumber sebelumnya disebutkan bahwa pertukaran informasi tersebut dapat melaui suatu wadah/komunitas. Di dalam komunitas tersebutlah UMKM secara aktif untuk berbagi informasi, namun hal ini akan signifikan disertai pemanfaatan teknologi infomasi dengan saling menjaga informasi diantara pemasok yang dapat mempengaruhi mitra lain sehingga pertukaran informasi dapat terwujud dengan baik.

Pada UMKM Bekasi dimana diperoleh hasil penelitian tidak terdapat pengaruh signifikan antara Teknologi informasi terhadap Performa supply chain. Pada sumber sebelumnya disebutkan bahwa masih rendahnya pemanfaatan Teknologi oleh UMKM yaitu 13\%. Untuk penelitian selanjutnya diharapkan sebelum meneliti terkait teknologi dan pengaruhnya terhadap performa supply chain diteliti atau dikaji terlebih dahulu mengenai bagaimana pemanfaatan teknologi itu sendiri pada UMKM. Kemudian diberikan rujukan teknologi informasi apa yang tepat untuk UMKM tersebut, kemudian baru dilakukan penelitian lebih lanjut mengenai pengaruh teknologi informasi terhadap performa supply chain.

Selain itu, pengaruh pertukaran informasi juga tidak berpengaruh signifikan terhadap performa supply chain UMKM Bekasi. Hal ini tidak senada dengan dugaan penelitian sebelumnya yang mengindikasikan adanya hubungan yang signifikan antara pertukaran informasi dan performa supply chain. Hasil penelitian menyebutkan untuk mendapatkan model yang FIT diperlukan pertukaran informasi dengan Pelaku UMKM, berbagi proses bisnis inti dengan Pelaku UMKM, dan saling menjaga informasi yang dapat mempengaruhi mitra lainnya. Selain itu, berbagi informasi dan berbagi proses bisnis inti diantara pemasok dan UMKM harus saling berhubungan. Pada penelitian ini adalah penelitian terhadap UMKM yang telah menggunakan teknologi informasi dan hasil peneltian menyebutkan mayoritas menggunakan media sosial. Pertukaran informasi itu sendiri dapat melalui suatu wadah, namun masih rendah UMKM yang masuk ke dalam wadah/komunitas sehingga hal tersebut tidak signifikan dalam meningkatkan performa supply chain. Karena melalui suatu wadah/komunitas UMKM dapat lebih mudah untuk bertukar infromasi.

\section{Ucapan Terima Kasih}

Peneliti mengucapkan terima kasih kepada DIPA Direktorat Jenderal Pendidikan Tinggi, Kementerian Pendidikan, Kebudayaan, Riset, dan Teknologi Tahun Anggaran 2021 atas dukungan dana penelitian yang telah diberikan dan Universitas Pelita Bangsa yang telah memfasilitasi pengajuan penelitian dasar dan pembinaan/kapasitas pada kontrak penelitian Nomor 037/KP/7.NA/UPB/II/2021 sehingga penelitian dapat dilaksanakan dengan baik. 


\section{Referensi}

Afolayan, A., Plant, E., White, G. R. T., Jones, P., \& Beynon-Davies, P. (2015). Information Technology Usage in SMEs in a Developing Economy. Strategic Change, 24(5), 483-498. https://doi.org/10.1002/jsc. 2023

Alfatiyah, R. (2020). Supply Chain Management Di Tengah Polemik Pandemi Covid-19. Industri Unpam.

Asmuni, I. (2014). PERANAN TEKNOLOGI DALAM SUPPLY CHAIN. Proseding Seminar Bisnis \& Teknologi, 15-16.

Bahri, S., \& Zamzam, F. (2021). Model Penelitian Kuantitatif Berbasis SEM AMOS (1st ed.). Deepublish Publisher.

Binus.ac.id. (2017). PENTINGNYA KOMUNITAS BISNIS BAGI START-UP. Binus.Ac.Id https://binus.ac.id/malang/2017/05/pentingnya -komunitas-bisnis-bagi-start-up/

Binus. (2019, November). TEKNOLOGI INFORMASI SEBAGAI PENGGERAK UTAMA SUPPLY CHAIN MANAGEMENT. Binus University.

Cahyono, T. (2018). Statistika Terapan dan Indikator Kesehatan (1st ed.). Deepublish.

Dametew, A. W., Ebinger, F., \& Abebe, B. B. (2016). Supply Chain Integration for Improving Performance on Manufacturing Industries. Global Journal of Researches in Enginering: J General Engineering , 16(4). https://www.researchgate.net/publication/3116 75737

Gray, D. E. (2014). Doing Research in The Real World (3rd ed.). SAGE Publications Inc.

Haryono, S., \& Wardoyo, P. (2015). Structural Equation Modeling untuk Penelitian Manajemen Menggunakan AMOS 18.00. In Dictionary of Statistics \& Methodology. PT Internedia Personalia Utama. https://doi.org/10.4135/9781412983907.n1909

Hendayani, R., \& Febrianta, Y. (2020). Technology as a driver to achieve the performance of family businesses supply chain. J. Fam. Bus. Manag. https://doi.org/10.1108/JFBM-102019-0070

Herman. (2019, November). UMKM Didorong Masuk Rantai Pasok Global. Beritasatu. https://www.beritasatu.com/ekonomi/585207/ umkm-didorong-masuk-rantai-pasok-global

Hikam, H. A. Al. (2020). Luhut: Banyak UMKM Belum Melek Digital. DetIkFinance.

Jadhav, V. V. (2015). Role of Information Technology in Supply Chain Management. Journal of Chemical Information and Modeling, 5(6), 369-379.

Junida, A. I. (2020). LIPI: Lebih dari 94 persen
UMKM turun penjualan karena pandemi. Antara News.

Kocoglu, I., Imamoglu, S. Z., Ince, H., \& Keskin, H. (2011). The Effect of Supply Chain Integration on Information Sharing: Enhanching the Supply Chain Performance. 7th International Strategic Management Conference, 16301649.

kompas. (2021, September). Digitalisasi Kunci Bertahan UMKM Hadapi Pandemi. Kompas.Id.

LIPI. (2020). Survei Kinerja UMKM di Masa Pandemi COVID19. LIPI.

liputan6.com. (2021). 4 Cara Agar UMKM Bisa Bertahan di Masa Pandemi. Liputan6.Com. https://id.berita.yahoo.com/4-cara-agar-umkmbisa-010007665.html

Lotfi, Z., Mukhtar, M., Sahran, S., \& Zadeh, A. T. (2013). Information Sharing in Supply Chain Management. Procedia Technology, 11(Iceei), 298-304. https://doi.org/10.1016/j.protcy.2013.12.194

Media Indonesia. (2021). Upaya Memperkuat UMKM di Masa Pandemi Covid-19. Medcom.Id.

Mofokeng, T. M., \& Chinomona, R. (2019). Supply chain partnership, supply chain collaboration and supply chain integration as the antecedents of supply chain performance. South African Journal of Business Management, 50(1), 1-10. https://doi.org/10.4102/sajbm.v50i1.193

Munizu, M. (2017). Pengaruh Kepercayaan, Komitmen, Dan Teknologi Informasi Terhadap Kinerja Rantai Pasokan (Studi Kasus Ikm Pengolah Buah Markisa Di Kota Makassar). Jurnal Manajemen Dan Agribisnis, 14(1), $32-42$. https://doi.org/10.17358/jma.14.1.32

Nabila, A. W., \& Er, M. (2019). Pengaruh Teknologi Informasi dalam Pertukaran Informasi dan Integrasi Rantai Pasok terhadap Performa Rantai Pasok. Sisfo, 08(03). https://doi.org/10.24089/j.sisfo.2019.05.005

Oktari, R. (2021, September). Dorong UMKM Masuk Rantai Pasok Global. Indonesiabaik.Id. https://indonesiabaik.id/videografis/dorongumkm-masuk-rantai-pasok-global

Purnamasari, D. M. (2020). Menurut Wapres, hanya 13 persen UMKM Sudah Memanfaatkan Teknologi Digital. Kompas.Com.

Rachbini, W., \& Rachbini, D. J. (n.d.). Metode Riset Ekonomi \& Bisnis (Analisis Regresi-SPSS \& SEM - Lisrel). Universitas Mercu Buana.

Santosa, S. (2018). Konsep Dasar dan Aplikasi SEM dengan AMOS 24 (1st ed.). PT Elex Media Komputindo. https://books.google.co.id/books?id=BLFfDw 
AAQBAJ\&printsec $=$ frontcover $\& d q=$ analisis + data+SEM\&hl=id\&sa=X\&ved=2ahUKEwiyq KCYrdXsAhVv7XMBHRyJCUgQ6AEwAno ECAIQAg\#v=onepage\&q=JUMLAH SAMPEL $\& \mathrm{f}=$ false

Schumacker, R. E., \& Lomax, L. G. (2016). A Beginner's Guide to Structural Equation Modeling, 4th ed (4th ed.). Taylor \& Francis.

Situmorang, A. P. (2021, September 3). Rasio Produk UMKM RI di Rantai Pasok Global Masih Rendah, Kalah Dibanding Malaysia. Merdeka.Com.

https://www.merdeka.com/uang/rasio-produkumkm-ri-di-rantai-pasok-global-masih-rendahkalah-dibanding-malaysia.html

Solimun, A. A. R. F., \& Nurjannah. (2017). Metode Statistika Multivariat Pemodelan Persamaan Struktural (SEM) Pendekatan WarpPLS, (2nd ed.). UB Press.

Som, J. O., Cobblah, C., \& Anyigba, H. (2019). The Effect of Supply Chain Integration on Supply Chain Performance. SSRN Electronic Journal, January 2019. https://doi.org/10.2139/ ssrn.3468798

Subburaj, A., Sriram, V. P., \& Mehrolia, S. (2020). Effects of supply chain integration on firm's performance: a study on micro, small and medium enterprises in India. Uncertain Supply Chain Management, 8(1), 231-240. https://doi.org/10.5267/j.uscm.2019.7.001
Sundram, V. P. K., Chhetri, P., \& Bahrin, A. S. (2020). The Consequences of Information Technology, Information Sharing and Supply Chain Integration, towards Supply Chain Performance and Firm Performance. Journal of International Logistics and Trade, 18(1), 15-31. https://doi.org/10.24006/JILT.2020.18.1.015

Ucenic, C. I., \& Ratiu, C. (2017). Improving Performance in Supply Chain. MATEC Web Conf, 137, 1-6. https://doi.org/10.1051/ matecconf/201713701018

Uyun, M., Eva, N., \& Lutvi, Y. (2021). Confirmatory Factor Analysis untuk Penelitian Psikologi dengan AMOS dan SMARTtPLS (1st ed.). PT Human Persona Indonesia.

Varma, T. N., \& Khan, D. A. (2014). Information Technology in Supply Chain Management. Journal of Supply Chain Management Systems, 3(3), 35-46. https://doi.org/ 10.18000/ijisac.50015

Wijaya, A., \& Spss, A. (2011). s Structural Equation e r p Modelling daidklatwws robys mo idkl at $w$ ws droserpcm. 